\title{
Characterization of Human Dermal Papilla Cells in Alginate Spheres
}

\author{
Nanda Maya Mali ${ }^{1,2,+}$, Yong-Hee Kim ${ }^{4, \dagger}$, Jung Min Park ${ }^{1,2}$, Donghyun Kim ${ }^{1,2}$, Wook Heo ${ }^{1,2}$, \\ Buu Le Dao ${ }^{5}$, Jeong Ok Lim ${ }^{2,3, *}$ and Ji Won Oh 1,2,3,*(D) \\ 1 Department of Anatomy, Kyungpook National University School of Medicine, 680 Gukchaebosang-ro, \\ Daegu 41944, Korea; malinanda8@gmail.com (N.M.M.); joelle7554@gmail.com (J.M.P.); \\ dhkim1714@gmail.com (D.K.); medwheo@gmail.com (W.H.) \\ 2 Department of Biomedical Science, Biomedical Research Institute, Kyungpook National University, \\ Daegu 41940, Korea \\ 3 Joint Institute for Regenerative Medicine, Kyungpook National University Hospital, Daegu 41940, Korea \\ 4 Department of Microbiology, Kyungpook National University School of Medicine, 680 Gukchaebosang-ro, \\ Daegu 41944, Korea; tolerance@knu.ac.kr \\ 5 Department of Developmental and Cell Biology, University of California, Irvine, CA 92697, USA; \\ daobl@uci.edu \\ * $\quad$ Correspondence: jolim@knu.ac.kr (J.O.L.); ohjiwon@knu.ac.kr (J.W.O.); Tel.: +82-53-420-6950 (J.O.L.); \\ +82-53-420-4806 (J.W.O.); Fax: +82-53-427-5447 (J.O.L.); +82-53-427-5664 (J.W.O.) \\ + These authors contributed equally to this work.
}

Received: 20 July 2018; Accepted: 3 October 2018; Published: 19 October 2018

\begin{abstract}
Maintenance of trichogenecity of dermal papilla cells (DPCs) have been a problem during cell therapy for androgenic alopecia, as they lose their regenerative potential in in vitro culture. Various spheroid culture techniques are used to increase and maintain trichogenecity of these cells. However, there are some critical drawbacks in these methods. Applying a hydrocell plate for sphere formation or hanging drop methods by hand would be difficult to control the size and cell density inside it. It would be difficult to commercialize or mass production for clinical therapy. In aim to address and overcome these drawbacks, we have introduced alginate sphere. The alginate sphere of DPCs were prepared by electrospinning at different voltages to control the size of sphere. Then the obtained alginate spheres were evaluated for cellular dynamics and density of DPCs under different conditions. In this study, we found that DPCs do not proliferate in alginate sphere. However, the number of DPCs were maintained and found to be in dormant state. Further, the dormant DPCs in the alginate sphere have upregulated DPC signature genes (SOX2, ALPL, WIF1, Noggin, BMP4 and VCAN) and proliferative capacity. Thus, we speculate that alginate sphere environment maintains the dormancy of DPCs with increased trichogenecity.
\end{abstract}

Keywords: alginate sphere; dermal papilla cell; trichogenecity; dormancy

\section{Introduction}

Physiologically, each cell and organ has a position in three dimensions. In vivo, the cells in each tissue can interact with other cells in every available direction, unlike in vitro cell cultivation. To restore the cellular properties to restricted cell culture systems, a spherical formation is commonly used to enhance and restore cellular function [1,2]. It is well known that cells lose their regenerative potential during in vitro cultivation [3]. However, three-dimensional cultivation, especially in a spherical shape, is used in maintaining cellular potential and properties to differentiate functionally $[4,5]$.

Human hair follicle dermal papilla cells (DPCs) can be cultured in a spheroid for the induction of hair-follicle neogenesis [6,7]. Hair follicles are known to have cyclic interaction between the 
epithelial compartment and mesenchymal compartment $[8,9]$. In the proliferation stage-called anagen - the epithelial cells (matrix cells) around the DPCs are highly proliferative and differentiate into the components of the hair shaft. It is assumed that dermal papilla cells interacting with epithelial population control the initiation of the hair cycle and the maintenance of the duration of anagen [10]. Intriguingly, during the mature anagen stage, the time of the hair follicle growth, DPCs are not proliferative compared to proliferative matrix cells in the hair follicle. DPCs are highly regulated autonomously; the cells from the connective tissue sheath join DPCs and proliferate in early anagen [11-13]. After this stage, the total number of DPCs are strictly maintained during mature anagen [14]. These DPCs provide instructive signals required to activate and initiate hair follicle regeneration [15]. Though dermal papilla is an important component in the biology of the hair follicle, the scientific research is mainly focused on the characteristics of DPCs in in vitro cultivation, especially in humans because of lack of experimental tools $[16,17]$.

Previously, it was reported that human DPCs in spherical form have the potential to generate a new hair follicle combined with trichogenetic neonatal mouse competent epithelial cells in a hair induction assay [18]. In rat, even cultured DPCs can make new hair follicle [19]. However, it is reported that after DPCs are removed from the hair follicle in vivo, they tend to lose their ability to make new hair follicles in cultivation [20]. Though the DPCs are known to lose this ability after serial passage, it is reported that factors such as Bone Morphogenetic Protein (BMP) and keratinocyte-conditioned media can maintain their ability after cultivation [20,21]. Furthermore, DPCs in spheroid have been reported that were similar to in vivo DP morphologically and in DP signature. These 3D spheres can induce human follicle formation [6,7]

Recently, it was also shown that the spherical formation generated by a hydrocell binding plate could restore the ability of human hair DPCs to perform neogenesis [18]. Applying a hydrocell plate to human cell therapy, however, has critical drawbacks. First, handling each dermal papilla sphere by hand is burdensome and thus would be difficult to commercialize or mass production for clinical use in patients. Second, it is not possible to control the size of the spheres generated because their size is highly dependent on the quality of each hydrocell plate; therefore, homogeneously sized spheres cannot be easily produced. Third, the control of the cellular density is impossible because the mechanical forces from hydrocell plates can prevent cellular aggregation. Because of these inescapable forces, the size of the sphere is proportionated to the total number of cells inserted inside the plate.

To overcome the weaknesses of using a hydrocell plate, we generated a spherical formation using the alginate and electrospinning method [22]. Using this method, spheres can be produced not only homogeneously but also without dealing with each individual cell by hand [23]. Furthermore, by using different electrical voltages and flow velocities, we can also control the size of each sphere as well as the density of the human DPCs.

To induce functional restoration of DPCs, we fabricated a spherical scaffold using alginate. In this study, we evaluated the cellular dynamics of human DPCs in the alginate sphere under different conditions at the matter of size as well as cellular density within a confined alginate sphere. We speculated on the character of alginate spheres containing DPCs and established the optimal conditions to maintain cell numbers required for keeping DPCs in trichogenecity. It is expected that the spheres could enable the long-term cultivation of DPCs for more than 60 days, leading us to find a unique quiescent property of stem cell dormancy in the human DPCs in the alginate spheres.

\section{Materials and Methods}

\subsection{Isolation of Human Hair Follicles}

Punch biopsy specimens $(3 \mathrm{~mm})$ were obtained from the occipital scalps of male patients undergoing hair transplant surgery. The Medical Ethical Committee of the Kyungpook National University Hospital (Korea) approved all the procedures described. Informed written consent was obtained from the patients. The hair follicles were isolated and cultured by the method described 
with minor modifications [24]. Briefly, the subcutaneous fat of the scalp skin, including the lower hair follicles, was dissected from the epidermis and dermis. The hair follicles were then isolated under a binocular microscope with forceps.

\subsection{Culture of Dermal Papilla Cells}

The DPCs were isolated and cultured by the method described with minor modifications $[25,26]$. DPCs were isolated from the bulbs of dissected hair follicles, transferred onto plastic dishes coated with bovine type I collagen and cultured in Dulbecco's modified Eagle's medium (DMEM; Gibco BRL, Gaithersburg, MD, USA) supplemented with penicillin (100 U/mL), streptomycin $(100 \mathrm{mg} / \mathrm{mL})$ and $20 \%$ heat-inactivated fetal bovine serum (FBS) at $37{ }^{\circ} \mathrm{C}$ in a humidified atmosphere of $5 \% \mathrm{CO}_{2}$. The explants were left for 5 days and the medium was changed every 3 days. After the cell outgrowth became sub-confluent, the cells were harvested with $0.25 \%$ trypsin and $10 \mathrm{mM}$ EDTA in Hank's balanced salt solution (HBSS) and sub-cultured with a split ratio of 1:3. Afterwards, the DPCs were maintained in DMEM supplemented with $10 \%$ FBS.

\subsection{Fabrication of Alginate Microencapsulated Cells Using Electrospinning}

In brief, $1 \%$ medical grade alginic acid was mixed gently with cells at different ratios $\left(5 \times 10^{4}\right.$, $1 \times 10^{5}, 2 \times 10^{5}$ and $5 \times 10^{5}$ ). The mixture was transferred into a $10 \mathrm{~mL}$ syringe (Norm-Ject, Henke Sass Wolf, Tuttlingen, Germany) and then connected to a metal $25 \mathrm{G}$ nozzle gauge (Nano NC, Seoul, Korea). The syringe was placed on the syringe pump (ESN-EP100, ES-Pump ${ }^{\circledR}$, Eagan, MN, USA) of the electrospinning system (Nano NC, Seoul, Korea) and the parameters of the system were fixed at $7 \mathrm{kV}$ with a $10 \mathrm{~mL} / \mathrm{h}$ flow rate. To produce varied sizes of spheres, we changed the voltage $\pm 15 \%$ and flow rate $\pm 25 \%$ as needed. A beaker containing $1 \%$ of $\mathrm{CaCl}_{2}$ (Sigma, St. Louis, MO, USA) was placed approximately $5 \mathrm{~cm}$ under the syringe pump to allow the cross linkage and formation of microbeads containing cells upon the spraying of the mixture under a power supply. The fabricated microbeads were sieved using a 100- $\mu$ m cell strainer (BD Falcon ${ }^{\mathrm{TM}}$, Durham, NC, USA) and further rinsed with distilled water prior to culturing in medium. We used passage 3-4 dermal papilla cells in vitro cultivation for the making alginate microencapsulated sphere.

\subsection{Direct Cell Count}

For accurate determination of cell growth, the direct cell count method was conducted under a microscope and image analysis software (Olympus, Tokyo, Japan) was used. The number of cells grown and their viability was assessed by the direct counting method using $0.4 \%$ trypan blue dye. Each sphere was captured by image software provided by Olympus and the total cell number in a sphere was counted three dimensionally by manual.

\subsection{RNA Isolation and Real Time PCR}

Total RNA was isolated from the DPCs from the alginate spheres using a RNeasy Micro Kit (Qiagen, Haldien, Germany). For real-time PCR (qPCR) analyses, according to the manufacturer's protocol, cDNA was synthesized using SuperScript III First-Strand Synthesis SuperMix for qPCR (Invitrogen, Carlsbad, CA, USA). The qPCR analysis was performed using SYBR Green PCR Master Mix (Applied Biosystems, Santa Clara, CA, USA) and a real-time PCR system (Applied Biosystems, Santa Clara, CA, USA). All the primers were designed using Primer Express software (Applied Biosystems), as described by Ohyama et al. [27].

The primer sets used for the experiment are shown in Supplementary Table S1. The reactions were performed under the suggested cycling conditions: polymerase activation for $10 \mathrm{~min}$ at $95^{\circ} \mathrm{C}$, followed by 45 cycles of $15 \mathrm{~s}$ at $95^{\circ} \mathrm{C}$ and $60 \mathrm{~s}$ at $60^{\circ} \mathrm{C}$. For all PCR experiments, post-PCR DNA melt curve analysis was performed to assess amplification specificity. DNA melting was carried out using a temperature ramping rate of $0.2{ }^{\circ} \mathrm{C}$ per step with a 30-second rest at each step. The quantification of RNA was done using the nanodrop method, $1 \mu \mathrm{g}$ cDNA was used for qPCR. Target RNA expression 
level was normalized to the house keeping gene GAPDH RNA using the $\Delta \mathrm{Ct}$ method. The relative fold was calculated as $2^{-\Delta \mathrm{Ct}}$ [28]. Three independent experiments were conducted for the reproducibility.

\subsection{CMDil Labeling of Cells}

To trace the implanted cells in the scaffold, the cells were labeled with CMDil (Invitrogen, Carlsbad, CA, USA) according to the manufacturer's protocols with modification [18]. Briefly, the cells were incubated for $20 \mathrm{~min}$ at $37^{\circ} \mathrm{C}$ with the CMDil solution. After incubation, the cells were washed with DPBS (Invitrogen, Carlsbad, CA, USA) to remove the residuals of CMDil. The labeled cells were detected using immunofluorescent microscope or a confocal microscope (Olympus, Tokyo, Japan).

\subsection{Cultivation of Explants}

Human DP were isolated from the bulbs of dissected hair follicles. Right after dissection, human DP is transferred onto plastic dishes coated with bovine type I collagen and cultured with Dulbecco's modified Eagle's medium (DMEM; Gibco BRL, Gaithersburg, MD, USA) supplemented with penicillin $(100 \mathrm{U} / \mathrm{mL})$, streptomycin $(100 \mathrm{mg} / \mathrm{mL})$ and $10 \%$ heat-inactivated fetal bovine serum (FBS) at $37{ }^{\circ} \mathrm{C}$ in a humidified atmosphere of 5\% $\mathrm{CO}_{2}$. We cultivated the explant only 20-30 days. Before RNA isolation, we washed explant (ex vivo) of human DP with $1 \times$ PBS. Explant of Alginate 3D sphere is defined as the cultivated cellular component within alginate at specific dates. After cultivation within the alginate spheres for short-term (D10), mid-term (D50) and long-term (D80), every alginate sphere was cut randomly into small pieces. The cells from alginate grow in DMEM supplemented with $10 \% \mathrm{FBS}$, penicillin $(100 \mathrm{U} / \mathrm{mL})$, streptomycin $(100 \mathrm{mg} / \mathrm{mL})$ at $37^{\circ} \mathrm{C}$ in a humidified atmosphere of $5 \% \mathrm{CO}_{2}$. We cultivated the explant only 20-30 days.

\subsection{Statistical Analysis and Normalization}

Every experiment was conducted by three times independently in duplicate to obtain enough statistical power. To present the data properly, every trials and conditions are shown in a box and whisker plot. Statistical analysis was performed using the R-Studio version 1.0.153 software program. For the comparison of cellular density and alginate size of each experimental condition, we used the normalization based on the volume of the average alginate sphere. Basically, we normalized total number of each cells in a specific sphere divided by the specific alginate volume measured by 3D virtual imaging (cell number $/ \mathrm{mm}^{3}$ ). Statically significant differences were calculated by Student $t$-test. A $p$-values of less than 0.05 was considered statistically significant.

\section{Results}

\subsection{Characteristics and Cultivation of Human Dermal Papilla Cells in In Vitro and in Alginate Spheres}

The human DPCs were physically micro-dissected and explanted onto the collagen I-coated dishes. The dermal papilla is located in the lower area of the hair follicle (Figure 1A). In this experiment, $83 \%$ of the DPCs were successfully cultivated. The rest of the dermal papillae were floating and could not grow on the plate (Figure 1B,C) because of surface tension. Though the melanin pigment and a small number of melanocytes were combined with the dermal papilla at the time we explanted them (Figure 1B), once we changed the media, the melanin pigment was washed away and the melanocytes were no longer growing. The dermal papillae were growing like sunflowers or target like patterns at first; however, as time passed, the cells spread out from the dermal papilla (Figure 1D). As the time passage continued, the DPCs proliferated and spread from their origin but the shape of the cells was subtly different and the size was larger than the explants of DPCs (Figure 1E). Beyond passage 10, the cells were considered as senescent cells; the proliferation of these cells were too slow and the size and shape of the cells was too dysmorphic to use them for the experiments. 

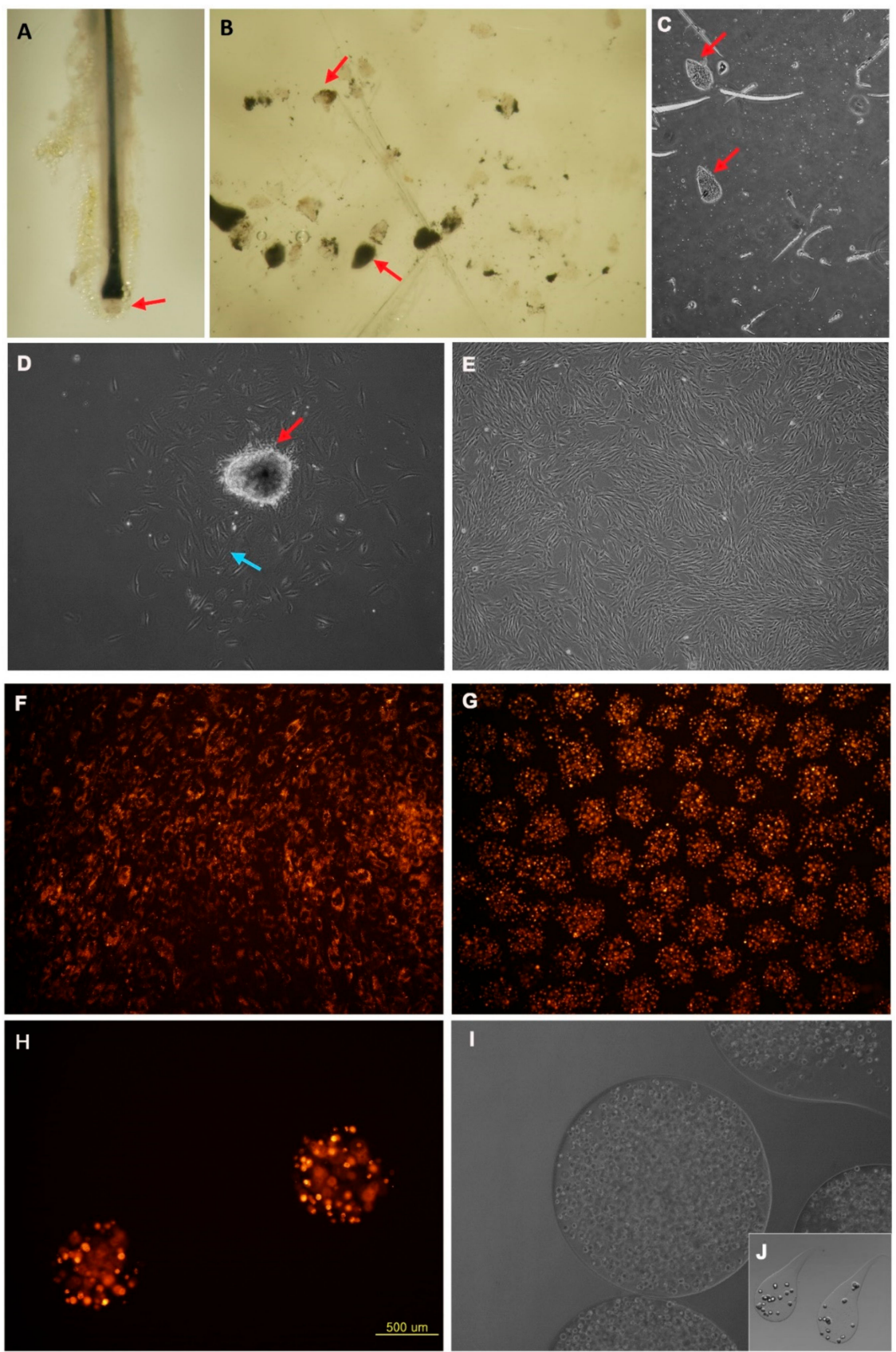

Figure 1. The culture characteristics of human DPCs and alginate spheres. (A) Human hair follicle in vivo (red arrow showed dermal papilla in hair bulb region). (B,C) Isolated human dermal papillae in vivo. (D) Five days after cultivation of the human dermal papilla (red arrow-dermal papilla and blue arrow-explant cells from dermal papilla). (E) Passage 3 of human DPCs. $(100 \times)$. (F) Conventional 2D culture state of human DPCs with CMDil. (G) Alginate sphere form of human DPCs with CMDil. (H) Cellular morphology after electrospinning. (I) The maximal size of the alginate spheres with human DPCs. (J) Tear drop shape of alginate with human DPCs. Scale bars in (A-G,J): $100 \mu \mathrm{m},(\mathbf{H}, \mathbf{I}) 500 \mu \mathrm{m}$.

Unlike traditional two-dimensional (2D) cultivation, spheres were three dimensionally cultivated (Figure 1F,G). The DPCs in 2D cultivation grew more rapidly than those in alginate spheres. The cells in the plate grew and expanded based on each cellular colony. However, the cells in the alginate were in the sphere after electrospinning (Figure 1H). Though the cells in the sphere were proliferative, the proliferation was generally lower than what we expected. The cellular density inside the sphere and the size of the sphere could be controlled by varying the voltage, alginate volume and flow velocity. 
The maximal size we could produce homogeneously was approximately $2000 \mu \mathrm{m}$; however, the growth and handling of the larger spherical formations were not adequate for this experimental purpose (Figure 1I). Although largest size we could make was more than $3000 \mu \mathrm{m}$, the cells in these spheres were too compact to speculate on the character of the DPCs. The smaller spheres, less than $1000 \mu \mathrm{m}$ in size, were better for the experimental purpose.

During electrospinning, more than $90 \%$ of the cells had a spherical shape (Figure 1I). Occasionally, we were able to find a teardrop-shaped alginate sphere (Figure 1J). The spheres tended to take on a teardrop shape if a more diluted alginate solution was used. We found that the smaller number of cells inside the sphere, the more round the cluster is.

\subsection{Effect of Different Size of Alginate Spheres on DPCs Proliferation}

To elucidate the effect of sphere size on the cell proliferation, we generated different sizes of spheres with the same cellular density. We could successfully produce 4 different sizes of alginate spheres homogenously. We classified them into 4 groups (small, middle, moderate and large). The average diameter of the spheres in the small group $(100-200 \mu \mathrm{m})$ was $151.85 \mu \mathrm{m}$ (Figure 2A), the middle size $(300-500 \mu \mathrm{m})$ was $394.85 \mu \mathrm{m}$ (Figure 2B), the moderate size $(500-1000 \mu \mathrm{m})$ was $733.90 \mu \mathrm{m}$ (Figure 2C) and large size group was more than $1000 \mu \mathrm{m}$ (Figure 2D). There were 84.5 $(77 \sim 93, \mathrm{n}=25)$ cells in the small spheres, including $76.7(68 \sim 87)$ live cells $(90.8 \%)$ and $7.8(4 \sim 10)$ dead cells (9.2\%) after electrospinning. Though we could control the size and density up to $1500 \mu \mathrm{m}$, the spherical formation tended to become irregular when the size reached more than $1000 \mu \mathrm{m}$ (large size group) and the variation in shape increased with increasing size (Figure $2 \mathrm{H}$ ). We occasionally found entrapped air in the large spheres right after electrospinning; however, it had disappeared within 24 hours, which meant that there were diffusive communications between the inside of the alginate sphere and outside surface (Figure 2D).

To investigate the short-term effects of the spherical formation, we studied the proliferation rate of the different sizes of spheres. Intriguingly, the DPCs did not seem to proliferate in any size of spherical formation (Figure 2E). Compared to 2D cultivation, in the spherical formation of alginate, DPCs did not tend to grow as quickly. Rather, in the middle-sized (300-500 $\mu \mathrm{m})$ and moderate-sized (500-1000 $\mu \mathrm{m})$ spheres, the number of live cells decreased slowly after the sphere formation. The total number of cells (live and dead cells both) did not significantly change in any size of spherical formation (Figure 2F). Considering that creating an alginate sphere as a method of entrapping DPCs inside a sphere, the dead cells would be caught in the sphere; but not washed out. Interestingly, the ratio of live to dead cells gradually decreased in the spheres of every size (Figure 2G). Though these were unexpected results, the tendency of the live cell number was decreasing. From this result, we concluded that the cells were non-proliferative and slowly dying. The larger the size of the sphere was, the more dramatic the rate of decrease was, which meant that the size dependent nutrition diffusion from the media might have been involved in the maintenance of cellular proliferation within alginate sphere.

Unexpected results of DPCs in alginate sphere led us to further investigate the cellular dynamics of the long-term cultivation. To characterize the long-term properties of the alginate spheres of human DPCs, we cultivated and traced them for 90 days. The cells inside the alginate sphere seemed not to proliferate but to remain and eventually died as time passed in alginate spheres of every size (Figure 2I-K). The total number of live cells decreased until 70 days after cultivation. Intriguingly, the live cell number remained steady after 70 days and was maintained until the last day of speculation, day 90 . There was a convergence phenomenon in the number of live cells in every size after 70 days (Figure 2I-K).

We found that every situation of alginate long-term cultivation can diminish the total live DPCs in alginate but after 70 days, the number of DPCs in alginate sphere were maintained. In the small size alginate sphere, the number of average live cells are 8.8 (4-12) cells at day 70, 7.8 (4-13) cells at day 80 and 7.1 (3-10) cells at day 90. In case of middle size, there are 97.1 (63-131) cells at day 70, 85.8 (50-111) cells at day 80 and $80.8(49-111)$ cells. In moderate size of alginate sphere, we found that their live cells 
are convergent to 598.6 (483-728) cells at day 70, 529 (440-591) cells at day 80 and 462.6 (375-592) cells at day 90 .

We next investigated whether this convergence was dependent on a particular parameter. We selected several candidate parameters to investigate: input cell number, diameter, surface area and volume of alginate sphere. The number of live cells at day 90 was highly dependent on the volume of the alginate spheres (Figure 2L). We could conclude that the volume itself was a parameter strongly related to this convergence phenomenon given its relationship with cellular number, leading optimal density. The remaining cellular density in average after the convergence was 2892.14 (day 70), 2555.87 (day 80), 2235.86 (day 90) cells per $\mathrm{mm}^{3}$ at the moderate size, 3012.32 (day 70), 2661.76 (day 80), 2506.64 (day 90) cells per $\mathrm{mm}^{3}$ at the middle size and 4799.31 (day 70), 4253.93 (day 80), 3872.16 (day 90) cells per $\mathrm{mm}^{3}$ at the small size respectively. The number of cells per $\mathrm{mm}^{3}$ after convergence tended to increase as the volume of the sphere decreases.

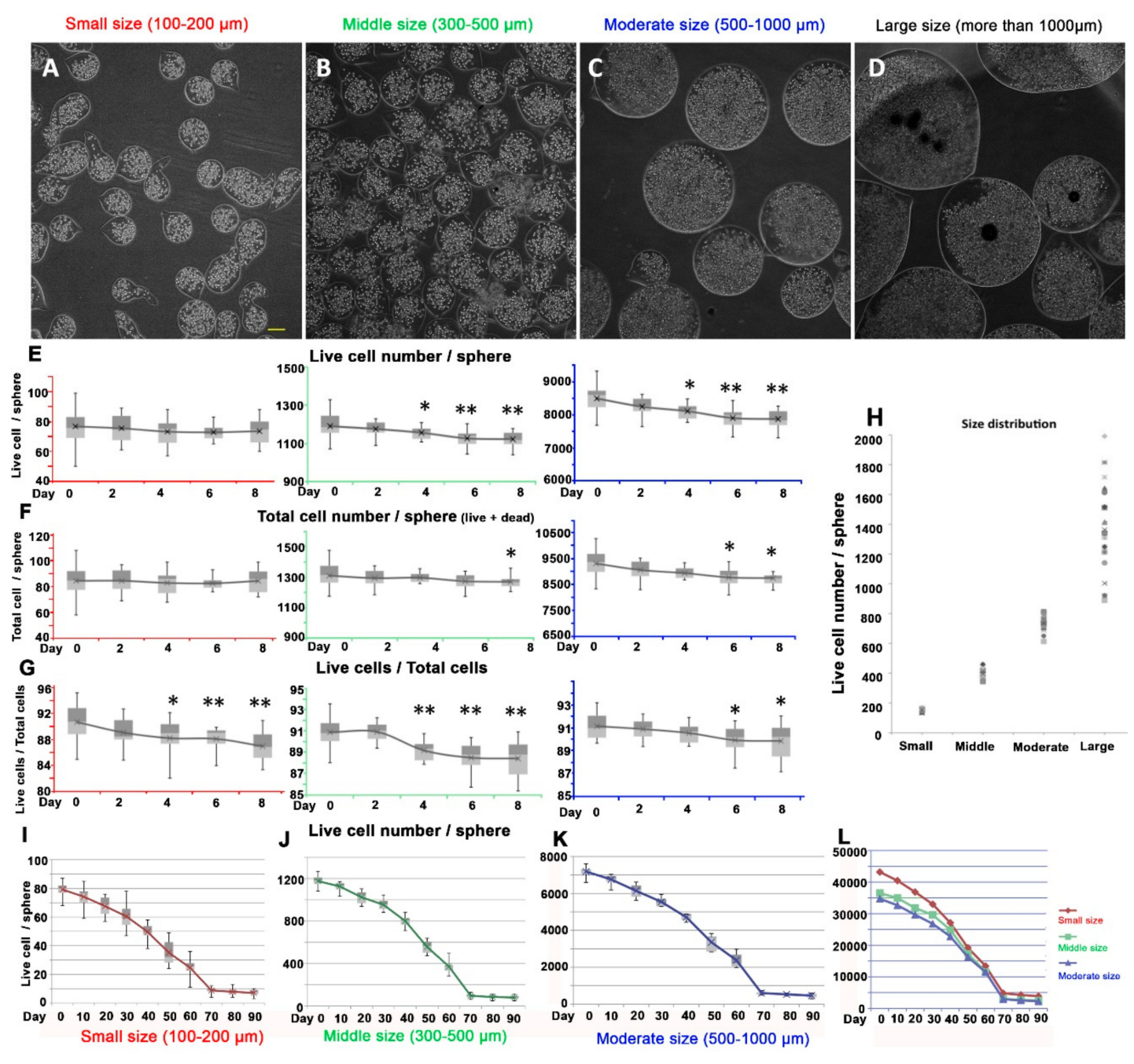

Figure 2. Short-term and long-term cultivation of dermal papilla alginate spheres in different sizes. (A-D) Different sizes of alginate spheres with human DPCs. (A) Small size (100-200 $\mu \mathrm{m}$ ). (B) Middle size $(300-500 \mu \mathrm{m})(\mathbf{C})$ Moderate size $(500-1000 \mu \mathrm{m})(\mathbf{D})$ Large size (more than $1500 \mu \mathrm{m})$. (E) Live cell number in different sizes of alginate spheres. (F) The number of total cells included live and dead cells in different size of alginate spheres. (G) The ratio of live cells to total cells in different sizes of alginate spheres. (H) The distribution of cell numbers in different sizes of alginate spheres. (I-K) Live cell number in small-size, middle size and moderate size respectively. (L) Normalized live cell number with the volume of the alginate spheres in different sizes of spheres. (Cell number $/ \mathrm{mm}^{3}$ ). Note. ${ }^{*}: p$-value $<0.05,{ }^{* *}: p$-value $<0.01$, compared to day 0 (control). Red color: Small size (100-200 $\left.\mu \mathrm{m}\right)$, green color: Middle size $(300-500 \mu \mathrm{m})$, Blue color: Moderate size $(500-1000 \mu \mathrm{m})$. Scale bar: $100 \mu \mathrm{m}$. 


\subsection{Effect of Cellular Density of Alginate Spheres on DPCs Proliferation}

To determine the effect of cellular density in the sphere on the proliferation of DPCs, we cultivated the spheres under the same spherical diameter but with different numbers of cells input. The diameter of each sphere was controlled approximately at $200 \mu \mathrm{m}$, since the diameter of dermal papilla in human hair follicles is around 100-250 $\mu \mathrm{m}$ depending on the bulb size and body location. To avoid generating alginate spheres with a tear drop shape, which resulted when the alginic acid was diluted, we also controlled the dilution ratio of the alginic acid and cellular media. As we expected, we could produce $3 \mathrm{D}$ alginate spheres containing different numbers of DPCs with a highly controlled size (Figure 3A-D). The average number of live cells were $31.8,60.8,115.3$ and 214.4 per sphere immediately after making the sphere.
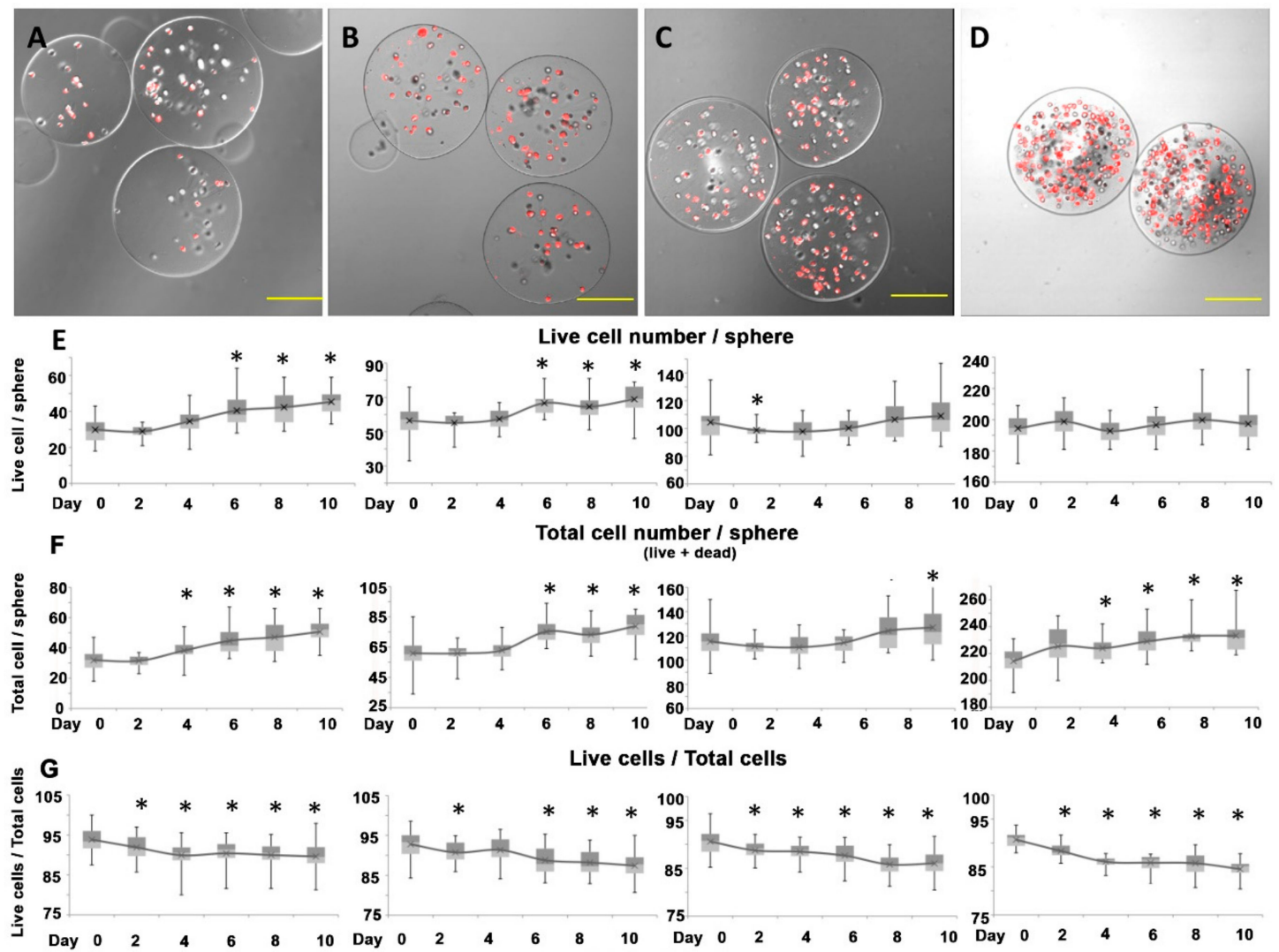

Live cells / Total cells

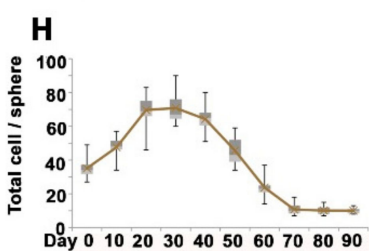

Total $5 \times 10^{4}$ cells
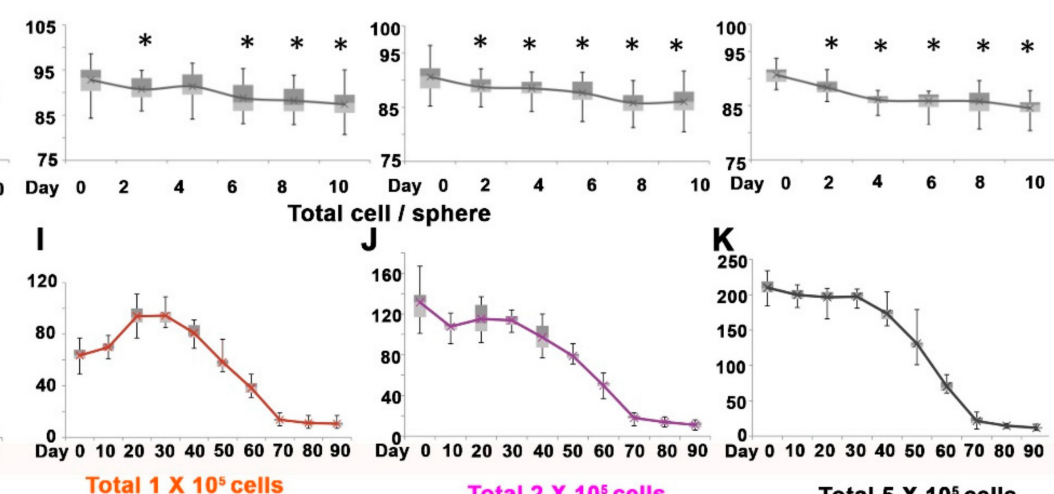

Total $2 \times 10^{5}$ cells

Total $5 \times 10^{5}$ cells

Figure 3. Short-term and long-term cultivation of dermal papilla alginate spheres with different cellular densities. (A-D): Different densities of alginate spheres. (A) low density, (B) middle density, (C) moderate density and (D) high density of human DPCs in alginate spheres. (E) The live cell number per alginate sphere at different cellular densities. (F) The total cells included both the live cells and dead cells per alginate sphere at different cellular densities. (G) The ratio of live cells to total cells per alginate sphere at different cellular densities. $(\mathbf{H}-\mathbf{K})$ : The live cell number with low density $(\mathbf{H})$, middle density $(\mathbf{I})$, moderate density $(\mathbf{J})$, high density $(\mathbf{K})$ of cells in a sphere (Cell number $/ \mathrm{mm}^{3}$ ). Note. *: $p$-value $<0.05, * *: p$-value $<0.01$. Compared to day 0 (control) as assessed by t-test. Scale bars: A-D: $100 \mu \mathrm{m}$. 
After we distributed DPCs inside the spheres in different densities, we followed the cell proliferation and survival rate. Unlike the experiment related to the size of the spheres, we observed cellular growth in the lower density spheres, particularly in the $5 \times 10^{4}$ and $1 \times 10^{5}$ density spheres (30-60 cells/sphere). We found that there was no growth in the higher density spheres with more than 100 cells/sphere (Figure 3E). Considering that the total number of cells (including live and dead cells) increased under all conditions in these experiments, we could conclude that there were cellular proliferations in all of the spheres at early time point. (Figure 3F). The lower the cell density was, the greater the growth rate. However, the growth rate was insignificant compared to that produced through $2 \mathrm{D}$ cultivation. The total proportion of live cells decreased steadily as in the previous experiment (Figure 3G).

To examine the effect of cellular density on the alginate spheres containing human DPCs, we cultivated them for 90 days. Unlike the size experiments, the cells inside the alginate spheres seemed to proliferate in the lower densities (Figure 3H,I). However, they tended to decrease in numbers after reaching a maximal number of cells at day 30. Compared to lower density, the live cells decreased as time passed in the higher densities (Figure 3J,K). The total number of live cells continued to decrease until 70 days after cultivation. Interestingly, the live cell number remained stable after 70 days and lasted until day 90 as in the size experiments. In the alginate spheres of every density, we observed a convergence phenomenon after 70 days (Figure $3 \mathrm{H}-\mathrm{K}$ ). Their diameters of each cellular density groups $\left(5 \times 10^{4}, 1 \times 10^{5}, 2 \times 10^{5}, 5 \times 10^{5}\right)$ were statistically similar, $203.4 \mu \mathrm{m}, 205.7 \mu \mathrm{m}, 203.3 \mu \mathrm{m}$ and $204.4 \mu \mathrm{m}$ respectively ( $p$-value: 0.073 , ANOVA). The number of live cells after convergence was around 10 cells per sphere in every condition, which inferred that the number of convergent cells was not dependent on the cell number we input but on the volume of the alginate sphere. Average normalized cell number in alginate sphere by volume at day 90 are 2284.73 (1895.67-2905.47) cells per $\mathrm{mm}^{3}$ in $5 \times 10^{4}$ cell condition, $2339.46(1754.69-3328.52)$ cells per $\mathrm{mm}^{3}$ in $1 \times 10^{5}$ cell condition, 2628.81 (1900.34-3800.68) cells per $\mathrm{mm}^{3}$ in $2 \times 10^{5}$ cell condition and 2624.10 (1789.16-3801.96) cells per $\mathrm{mm}^{3}$ in $5 \times 10^{5}$ cell condition respectively.

\subsection{Behavior of DPCs from the Alginate Sphere}

To study the proliferation capacity of remained dormant cells in long-term alginate sphere, we cut every alginate sphere into pieces after the cultivation in alginate sphere. When we started to cultivate DPCs in alginate sphere, we usually used passage 3-4 DPCs in vitro cultivation since they go into the senescent status in couple of more passages, in general passage 6 or more. We incubated dermal papilla for 10 days, 50 days and 80 days in alginate sphere, then we tried to cultivate the dormant cells by breaking the alginate sphere structures. We found that some of the spheres without breaking alginate sphere form had their own colonies beneath them like primary human DPC explants (Figure 4A). As shown in Figure 4B,C, their ability to grow and make colonies was similar as it was in normal in vivo dermal papillae. Considering that the cells in the alginate spheres were not proliferative, their ability to grow in the explants showed that the DPCs have trichogenic properties to induce hair follicle formation but the alginate spheres put the cells into a dormant state.

To check the proliferative ability of the dormant state, we used the CMDil trace method. This chemical is diluted once the cell divides. The cells taken from the alginate spheres rapidly grew and divided in the 2D plate (Figure 4D). However, their CMDil level was extremely low compared to that of the cells inside the alginate sphere, which meant that the cells from the alginate sphere have a high potential to divide (Figure 4E).

Next, every culture of the human DPCs in the alginate spheres showed the convergence phenomenon after day 70. We concluded that there was a certain rule for this convergence and that we could combine the parameters of cellular densities as well as size of sphere. In the cellular density experiment, every experiment showed convergence to a specific range of cell numbers no matter how many cells we put inside the alginate sphere (Figure 4F). At the same time, the sphere size experiment showed that the convergence was mainly dependent on the volume of the alginate sphere 
(Figure 4G). Considering that we controlled the alginate spheres so that they all had similar sizes in the experiment on cellular density, we could conclude that there is a certain rule for the convergence toward a specific cellular number in long-term cultivation.
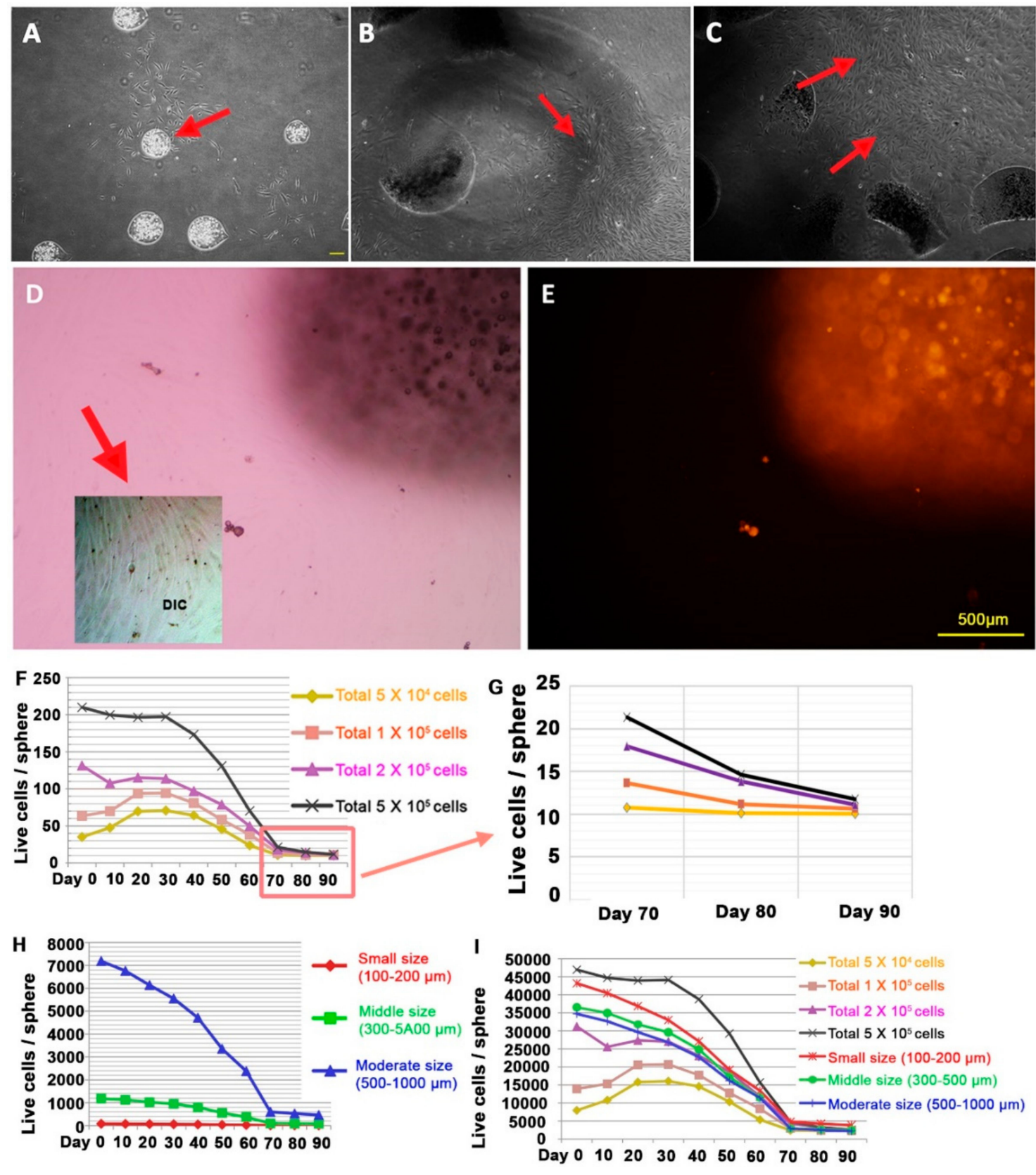

Figure 4. Cultivation of explants and cellular convergence rate of dermal papilla alginate spheres. (A-C) Colony forming properties of alginate spheres with human DPCs. (D,E) CMDil trace of cell culture from alginate sphere explants of human DPCs: light microscopy (D) and fluorescent microscopy (E). The subpanel of (D) is tone-modulated to show the diluted cells originated from CMDil retaining cells. The normalized live cell number with the volume of alginate spheres at different cellular densities (F) and different sizes (H). (G) The normalized live cell number with the volume of alginate sphere of different cellular densities at day 70, day 80 and day 90. (I) The normalized live cell number with the volume of alginate spheres under every experimental condition.

Reanalysis of our data after combining into single table and using the volume parameter as the candidate factor, we found the same convergence rate after 70 days (Figure $4 \mathrm{H}$ ). As we expected, the number of live cells was significantly dependent on the volume of the alginate spheres. 
The convergence density varied from 2235.05 cells $/ \mathrm{mm}^{3}$ to 3872.16 cells $/ \mathrm{mm}^{3}$. If we excluded the smallest size of alginate sphere, the range was between 2235.05 cells $/ \mathrm{mm}^{3}$ and 2628.80 cells $/ \mathrm{mm}^{3}$. Furthermore, these cells were highly dormant considering that they did not proliferate after being placed inside the alginate but simply remained static as they were in vivo.

\subsection{The Gene Expression Level of the Human DPCs in the Alginate Sphere}

Considering the cells after convergence were highly dormant, we hypothesized, that these cell populations were the putative human dermal papilla cells. We evaluated the gene expression level of the dermal papilla cell marker in vivo [27]. Human DPC signature genes expression is critical to speculate the trichogenic nature of DPCs in alginate spheres. As we expected, the expression level of these genes decreased after passage in 2D cultivation (Figure 5). The results suggest that the DPCs in alginate sphere remains the similar properties as DPCs in in vivo and it can induce hair follicle regeneration.
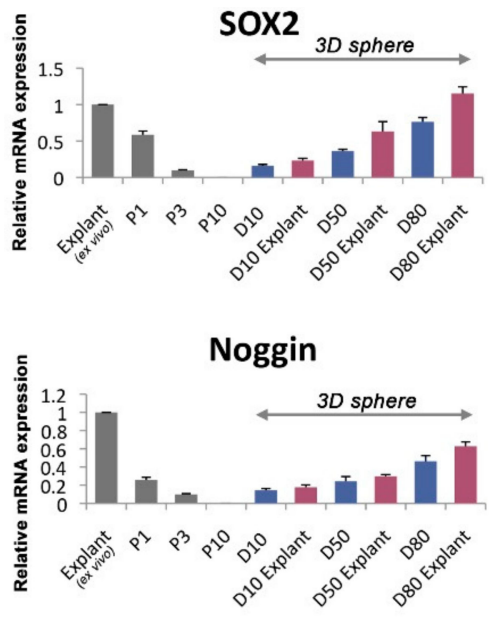

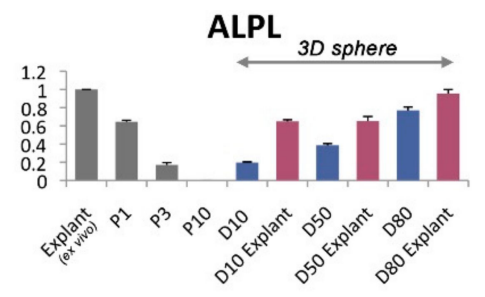

BMP4

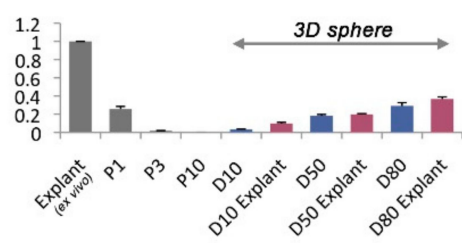

WIF1

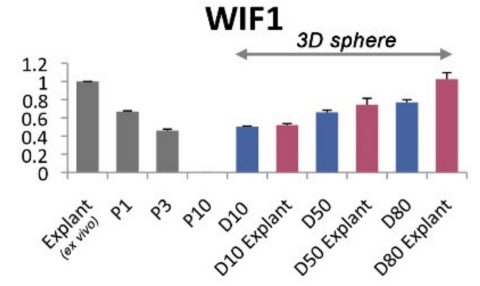

VCAN

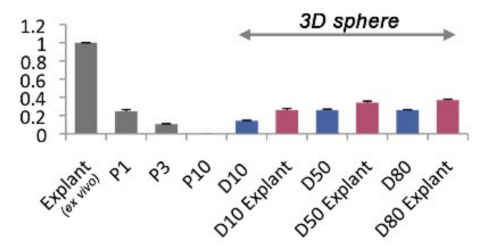

Figure 5. The gene expression level of dermal papilla alginate spheres by qPCR. The human dermal papilla cell marker genes expressed in different passage state and alginate spheres, cultivate in different days. Note. P1, P3, P10: passage state 1, 3 and 10 respectively. D10, D50, D80: post-spherical formation day 10,50 and 80 respectively.

In SOX2, WIF1 and ALPL, the gene expression was almost recovered to the level of the original explants (ex vivo). Intriguingly, the expression level increased as the 3D sphere cultivation was prolonged. Comparing 10 days after cultivation in the alginate sphere to 80 days, the latter showed a much higher gene expression level of SOX2, ALPL and WIF1. We assumed that the purity level of the stem cells might influence the expression level of the dermal papilla cell markers. Generally, the cells in the alginate sphere itself had a lower level of gene expression than explants from the sphere. Genes such as BMP4 and VCAN showed a slight recovery after cultivation in the alginate spheres.

\section{Discussion}

In the physiological state, the DPCs do not proliferate [9,29]. At the same time, they are highly functional, so they can interact with epithelial cells, which are mainly composed of matrix cells [29]. DPC is a permanent part of the hair follicle $[20,30]$. DPCs do not go into apoptosis so that they can re-enter the hair cycle though in the anagen-catagen transition there is a decrease in the number of cells in the DP, with migration to the DS [8,12]. Different intrinsic and extrinsic factors keep some of DPCs in dormancy, which helps to preserve stemness of these cells. Upon activation, the DPC exists from dormancy and/or quiescence to enter new cycle [31-34]. Compared with the in vivo state, once DPCs are cultivated, they are highly proliferating [35]. However, many studies have reported that DPCs lose their trichogenetic ability as the number of passages increases [20,35,36]. Many hair biologists 
have attempted to find a way to maintain the trichogenecity and the functional properties of DPCs after cultivation.

To recover the trichogenecity of human DPCs, we created alginate spheres containing human DPCs. To apply them in cell therapy for androgenetic alopecia, we investigated their cellular proliferation over the short-term and long-term. We concluded that the alginate spherical formation can regulate the DPCs so that they do not proliferate, as in physiological in vivo conditions. However, unlike in in vivo conditions, in 3D sphere formation, the number of cells is not maintained but decreases. Those short-term cellular number decreasing might be due to the condition of making alginate sphere such as voltage, $1 \%$ of $\mathrm{CaCl}_{2}$, or lysis caused by washing procedures of distilled water. However, its decreasing rate is consistent even after day 30 in alginate sphere, necessitating other reasons for explanation. If there is little secretory factor from the epithelial component, there is not sufficient proliferative potential in dermal papilla $[20,37,38]$. We recently reported that factors from the epithelial cells could induce and maintain DPCs' trichogenecity as well as modulate the regulation of DPC gene expression [39]. In further study, it would be worth to investigate the interactional effect of the secretory factors of epithelial cellular to the alginate sphere dormancy of dermal papilla cells.

Recently, our group has developed a method to recover trichogenecity of epithelial cells in 3D cultivation using a biodegradable scaffold $[24,40]$. We used sponge-type, fiber sheet and newborn epithelial skin scaffold (NESS) to restore the hair follicle formation properties of the cells. That study mainly focused on the epithelial compartment, not the mesenchymal compartment, although we investigated the nature of the epithelial-mesenchymal interaction. On the other hand, this study was carried out using DPCs. We investigated the effect of the cellular density as well as the size of the alginate sphere containing human DPCs. Intriguingly, though the number of live cells decreased, it was stabilized after 70 days of cultivation. We found that the cellular convergence number per alginate volume, the optimal cellular density in alginate, was not dependent on the number of cells we input but on the volume of the alginate sphere. Moreover, the average number of cells divided by the volume was similar after 70 days of cultivation, range between 2235.05 cells $/ \mathrm{mm}^{3}$ and 2628.80 cells $/ \mathrm{mm}^{3}$. We concluded that the remaining cells had to occupy a certain volumetric space or optimal density to maintain their properties.

Considering that the convergent number of cells in $200 \mu \mathrm{m}$ diameter alginate sphere is approximately around 10, while the cellular number of in vivo human DP ranges from 500 to 2000, in vivo human DP has much more cellular density than alginate sphere since Auber's line of human DP range from $80 \mu \mathrm{m}$ to $180 \mu \mathrm{m}$ in general depending on the body site of hair follicles [9]. There is a report that the cellular topology within dermal papilla and dermal sheath can have a different potential to regenerate [41]. Their group also reported the compartments above and below Auber's line have the heterogeneous hair inducing ability as well as their in vitro cultivation properties [42]. How to maintain their dormant status under optimal density within alginate sphere as well as what kind of dormant cells can survive in alginate sphere would be the critical questions in further study.

Our experiments have a limitation to elucidate why they do have their optimal density in alginate sphere with human dermal papilla cells. Specially to investigate whether they have any senescent characteristics would be an important question to address. It is also critical to note whether dermal sheath or dermal cup cell, which have more potential to be proliferative and considered as more mesenchymal stem cell property than dermal papilla cells, have similar characteristics in alginate sphere or not.

To determine the long-term characteristics of the cells remaining in the alginate spheres, we investigated the gene expression pattern of the DPC markers [27]. Signature genes including SOX2, ALPL, WIF1, Noggin, BMP4 and VCAN were up-regulated after cultivation in alginate spheres compared with normal 2D cultivation. Interestingly, in this experiment, the explants from the cells seeded in the alginate spheres expressed the signature genes more highly than $2 \mathrm{D}$ cells. The cells at 80 days after cultivation in the alginate spheres had the highest expression level of interested genes, 
which means that the remaining cells after cellular convergence in the alginate sphere are similar in nature to in vivo DPCs.

Compared with in vivo DPCs, DPCs in alginate spheres have distinct characteristics. We concluded that, in mature anagen stage, there are three main factors that make the dermal papilla functional: the dormancy factor, proliferative factor and maintenance factor (Figure 6). The dormancy factors cause DPCs to undergo dormancy to sustain stemness and the inductive characteristics of the cells. The proliferating factors, which in vivo DPCs do not have, cause the cells to grow. Normally, only during the short time between the telogen and anagen stages, the proliferating factors are enhanced in in vivo dermal papilla [12,13]. The maintenance factors are from the epithelial cells around the dermal papilla and cause the DPCs to remain alive. Compared to in vitro DPCs, DPCs in the alginate spheres had more of the dormancy factor and less of the proliferating factors giving the cells in the spheres more stem cell-like in vivo characteristics. We concluded that there are passive changes related to the dormant state and cellular death in $3 \mathrm{D}$ cultivation. The alginate sphere environment was found to maintain the dormancy of DPCs with increased trichogenecity.
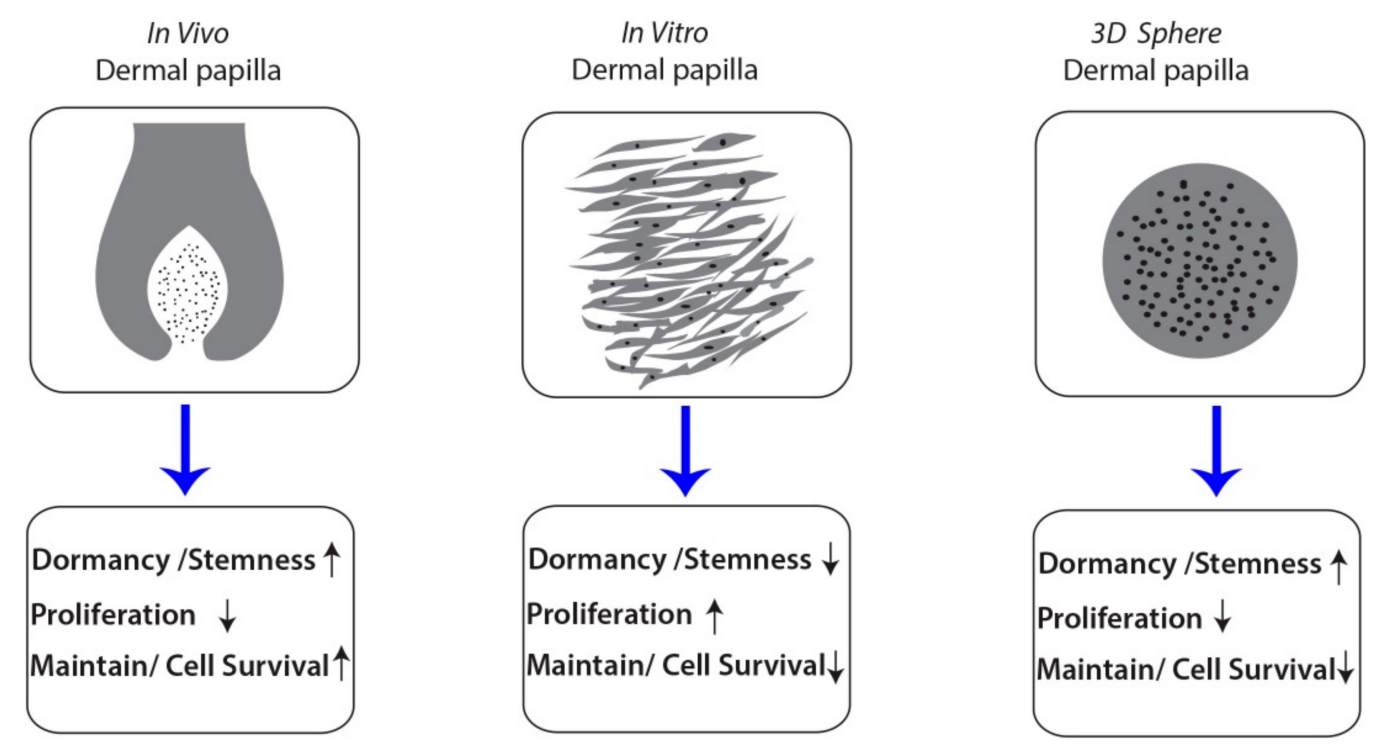

Figure 6. The figure showed the human dermal papilla in vivo, in vitro culture (2D) and alginate spheres (3D) and their characteristics of stemness, dormancy and proliferation state.

Our novel approach using alginate spheres demonstrates how DPCs behave inside the sphere microenvironment. The dynamics and the stem cell-like character of cells in alginate spheres are likely to be broadly applicable to hair biology as well as a number of complex model systems.

Supplementary Materials: The following are available online at http:/ /www.mdpi.com/2076-3417/8/10/1993/ s1, Table S1: Design of the primers used this study.

Author Contributions: J.W.O. and J.O.L. developed the concepts, designed the experimental methodology, analyzed the data, wrote, reviewed and approved the final paper. N.M.M. and Y.-H.K. conducted the experiments, analyzed the data, wrote and edited the paper. W.H., B.L.D., J.M.P. and D.K. conducted investigation of alginate sphere and cultivation.

Funding: This work was supported by Biomedical Research Institute grant, Kyungpook National University Hospital (2016).

Acknowledgments: The authors thank Jeong-Woo Choi for technical assistance.

Conflicts of Interest: The authors have no financial conflict of interest.

\section{References}

1. Mueller-Klieser, W. Three-dimensional cell cultures: From molecular mechanisms to clinical applications. Am. J. Physiol.-Cell Physiol. 1997, 273, C1109-C1123. [CrossRef] 
2. Fennema, E.; Rivron, N.; Rouwkema, J.; Van Blitterswijk, C.; De Boer, J. Spheroid culture as a tool for creating 3D complex tissues. Trends Biotechnol. 2013, 31, 108-115. [CrossRef] [PubMed]

3. Oh, J.W.; Hsi, T.C.; Guerrero-Juarez, C.F.; Ramos, R.; Plikus, M.V. Organotypic skin culture. J. Investig. Dermatol. 2013, 133, 1-4. [CrossRef] [PubMed]

4. Wang, W.; Itaka, K.; Ohba, S.; Nishiyama, N.; Chung, U.I.; Yamasaki, Y.; Kataoka, K. 3D spheroid culture system on micropatterned substrates for improved differentiation efficiency of multipotent mesenchymal stem cells. Biomaterials 2009, 30, 2705-2715. [CrossRef] [PubMed]

5. Suyama, T.; Hatta, M.; Hata, S.; Ishikawa, H.; Yamazaki, J. Differentiation of rat dermal mesenchymal cells and calcification in three-dimensional cultures. Tissue Eng. Regener. Med. 2016, 13, 527-537. [CrossRef]

6. Higgins, C.A.; Chen, J.C.; Cerise, J.E.; Jahoda, C.A.; Christiano, A.M. Microenvironmental reprogramming by three-dimensional culture enables dermal papilla cells to induce de novo human hair-follicle growth. Proc. Natl. Acad. Sci. USA 2013, 110, 19679-19688. [CrossRef] [PubMed]

7. Higgins, C.A.; Richardson, G.D.; Ferdinando, D.; Westgate, G.E.; Jahoda, C.A. Modelling the hair follicle dermal papilla using spheroid cell cultures. Exp. Dermatol. 2010, 19, 546-548. [CrossRef] [PubMed]

8. Stenn, K.; Paus, R. Controls of hair follicle cycling. Physiol. Rev. 2001, 81, 449-494. [CrossRef] [PubMed]

9. Oh, J.W.; Kloepper, J.; Langan, E.A.; Kim, Y.; Yeo, J.; Kim, M.J.; Hsi, T.-C.; Rose, C.; Yoon, G.S.; Lee, S.-J. A guide to studying human hair follicle cycling in vivo. J. Investig. Dermatol. 2016, 136, 34-44. [CrossRef] [PubMed]

10. Greco, V.; Chen, T.; Rendl, M.; Schober, M.; Pasolli, H.A.; Stokes, N.; Dela Cruz-Racelis, J.; Fuchs, E. A two-step mechanism for stem cell activation during hair regeneration. Cell Stem Cell 2009, 4, 155-169. [CrossRef] [PubMed]

11. Elliott, K.; Messenger, A.G.; Stephenson, T.J. Differences in hair follicle dermal papilla volume are due to extracellular matrix volume and cell number: Implications for the control of hair follicle size and androgen responses. J. Investig. Dermatol. 1999, 113, 873-877. [CrossRef] [PubMed]

12. Chi, W.; Enshell-Seijffers, D.; Morgan, B.A. De novo production of dermal papilla cells during the anagen phase of the hair cycle. J. Investig. Dermatol. 2010, 130, 2664-2666. [CrossRef] [PubMed]

13. Tobin, D.J.; Gunin, A.; Magerl, M.; Paus, R. Plasticity and cytokinetic dynamics of the hair follicle mesenchyme during the hair growth cycle: Implications for growth control and hair follicle transformations. J. Investig. Dermatol. Symp. Proc. 2003, 8, 80-86. [CrossRef] [PubMed]

14. Lichti, U.; Weinberg, W.C.; Goodman, L.; Ledbetter, S.; Dooley, T.; Morgan, D.; Yuspa, S.H. In vivo regulation of murine hair growth: Insights from grafting defined cell populations onto nude mice. J. Investig. Dermatol. 1993, 101, S124-S129. [CrossRef]

15. Rahmani, W.; Abbasi, S.; Hagner, A.; Raharjo, E.; Kumar, R.; Hotta, A.; Magness, S.; Metzger, D.; Biernaskie, J. Hair follicle dermal stem cells regenerate the dermal sheath, repopulate the dermal papilla and modulate hair type. Dev. Cell 2014, 31, 543-558. [CrossRef] [PubMed]

16. Kligman, A.M. The human hair cycle. J. Investig. Dermatol. 1959, 33, 307-316. [CrossRef] [PubMed]

17. Kwack, M.H.; Sung, Y.K.; Chung, E.J.; Im, S.U.; Ahn, J.S.; Kim, M.K.; Kim, J.C. Dihydrotestosterone-inducible dickkopf 1 from balding dermal papilla cells causes apoptosis in follicular keratinocytes. J. Investig. Dermatol. 2008, 128, 262-269. [CrossRef] [PubMed]

18. Kang, B.M.; Kwack, M.H.; Kim, M.K.; Kim, J.C.; Sung, Y.K. Sphere formation increases the ability of cultured human dermal papilla cells to induce hair follicles from mouse epidermal cells in a reconstitution assay. J. Investig. Dermatol. 2012, 132, 237-239. [CrossRef] [PubMed]

19. Oliver, R.F. The induction of hair follicle formation in the adult hooded rat by vibrissa dermal papillae. Development 1970, 23, 219-236.

20. Kishimoto, J.; Burgeson, R.E.; Morgan, B.A. Wnt signaling maintains the hair-inducing activity of the dermal papilla. Genes Dev. 2000, 14, 1181-1185. [PubMed]

21. Rendl, M.; Polak, L.; Fuchs, E. Bmp signaling in dermal papilla cells is required for their hair follicle-inductive properties. Genes Dev. 2008, 22, 543-557. [CrossRef] [PubMed]

22. Mun, C.H.; Hwang, J.Y.; Lee, S.H. Microfluidic spinning of the fibrous alginate scaffolds for modulation of the degradation profile. Tissue Eng. Regener. Med. 2016, 13, 140-148. [CrossRef]

23. Law, J.X.; Liau, L.L.; Saim, A.; Yang, Y.; Idrus, R. Electrospun collagen nanofibers and their applications in skin tissue engineering. Tissue Eng. Regener. Med. 2017, 14, 699-718. [CrossRef] 
24. Oh, J.W.; Choi, J.Y.; Kim, M.; Abdi, S.I.H.; Lau, H.C.; Kim, M.; Lim, J.O. Fabrication and characterization of epithelial scaffolds for hair follicle regeneration. Tissue Eng. Regener. Med. 2012, 9, 147-156. [CrossRef]

25. Shin, H.; Kwack, M.H.; Shin, S.H.; Oh, J.W.; Kang, B.M.; Kim, A.A.; Kim, J.; Kim, M.K.; Kim, J.C.; Sung, Y.K. Identification of transcriptional targets of wnt/beta-catenin signaling in dermal papilla cells of human scalp hair follicles: Ep2 is a novel transcriptional target of wnt3a. J. Dermatol. Sci. 2010, 58, 91-96. [CrossRef] [PubMed]

26. Kang, B.M.; Shin, S.H.; Kwack, M.H.; Shin, H.; Oh, J.W.; Kim, J.; Moon, C.; Moon, C.; Kim, J.C.; Kim, M.K.; et al. Erythropoietin promotes hair shaft growth in cultured human hair follicles and modulates hair growth in mice. J. Dermatol. Sci. 2010, 59, 86-90. [CrossRef] [PubMed]

27. Ohyama, M.; Kobayashi, T.; Sasaki, T.; Shimizu, A.; Amagai, M. Restoration of the intrinsic properties of human dermal papilla in vitro. J. Cell Sci. 2012, 125, 4114-4125. [CrossRef] [PubMed]

28. Livak, K.J.; Schmittgen, T.D. Analysis of relative gene expression data using real-time quantitative pcr and the 2(-delta delta c(t)) method. Methods 2001, 25, 402-408. [CrossRef] [PubMed]

29. Yang, C.-C.; Cotsarelis, G. Review of hair follicle dermal cells. J. Dermatol. Sci. 2010, 57, 2-11. [CrossRef] [PubMed]

30. Jahoda, C.A.; Horne, K.A.; Oliver, R.F. Induction of hair growth by implantation of cultured dermal papilla cells. Nature 1984, 311, 560-562. [CrossRef] [PubMed]

31. Flores, A.; Schell, J.; Krall, A.S.; Jelinek, D.; Miranda, M.; Grigorian, M.; Braas, D.; White, A.C.; Zhou, J.L.; Graham, N.A.; et al. Lactate dehydrogenase activity drives hair follicle stem cell activation. Nat. Cell Biol. 2017, 19, 1017-1026. [CrossRef] [PubMed]

32. Trumpp, A.; Essers, M.; Wilson, A. Awakening dormant haematopoietic stem cells. Nat. Rev. Immunol. 2010, 10, 201-209. [CrossRef] [PubMed]

33. Perry, J.M.; He, X.C.; Sugimura, R.; Li, L. Stem cell dormancy: Maintaining a reserved population. Rev. Cell Biol. Mol. Med. 2006. [CrossRef]

34. Wang, Q.; Oh, J.W.; Lee, H.L.; Dhar, A.; Peng, T.; Ramos, R.; Guerrero-Juarez, C.F.; Wang, X.; Zhao, R.; Cao, X.; et al. A multi-scale model for hair follicles reveals heterogeneous domains driving rapid spatiotemporal hair growth patterning. eLife 2017, 6, e22772. [CrossRef] [PubMed]

35. Rutberg, S.E.; Kolpak, M.L.; Gourley, J.A.; Tan, G.; Henry, J.P.; Shander, D. Differences in expression of specific biomarkers distinguish human beard from scalp dermal papilla cells. J Investig. Dermatol. 2006, 126, 2583-2595. [CrossRef] [PubMed]

36. Inamatsu, M.; Matsuzaki, T.; Iwanari, H.; Yoshizato, K. Establishment of rat dermal papilla cell lines that sustain the potency to induce hair follicles from afollicular skin. J Investig. Dermatol. 1998, 111, 767-775. [CrossRef] [PubMed]

37. Botchkarev, V.A.; Kishimoto, J. Molecular control of epithelial-mesenchymal interactions during hair follicle cycling. J. Investig. Dermatol. Symp. Proc. 2003, 8, 46-55. [CrossRef] [PubMed]

38. Wu, H.J.; Oh, J.W.; Spandau, D.F.; Tholpady, S.; Diaz, J., 3rd; Schroeder, L.J.; Offutt, C.D.; Glick, A.B.; Plikus, M.V.; Koyama, S.; et al. Estrogen modulates mesenchyme-epidermis interactions in the adult nipple. Development 2017, 144, 1498-1509. Available online: http:/ / dev.biologists.org/content/develop/144/8.toc. pdf (accessed on 19 July 2018). [CrossRef] [PubMed]

39. Lee, M.H.; Im, S.; Shin, S.H.; Kwack, M.H.; Jun, S.E.; Kim, M.K.; Kim, J.C.; Sung, Y.K. Conditioned media obtained from human outer root sheath follicular keratinocyte culture activates signalling pathways that contribute to maintenance of hair-inducing capacity and increases trichogenicity of cultured dermal cells. Exp. Dermatol. 2012, 21, 793-795. [CrossRef] [PubMed]

40. Choi, J.Y.; Oh, J.W.; Kim, S.J.; Lim, J.O. The effect of bsm-alginate sponge on the enhanced early proliferation of epithelial cells. Biomater. Res. 2013, 17, 26-30.

41. Matsuzaki, T.; Inamatsu, M.; Yoshizato, K. The upper dermal sheath has a potential to regenerate the hair in the rat follicular epidermis. Differentiation 1996, 60, 287-297. [CrossRef] [PubMed]

42. Yamao, M.; Toyoshima, K.-E.; Yoshizato, K. Comparison of hair-inducing ability between the upper and the lower dermal papilla: P4.44. J. Dtsch. Dermatol. Ges. 2004, 2, 526.

(C) 2018 by the authors. Licensee MDPI, Basel, Switzerland. This article is an open access article distributed under the terms and conditions of the Creative Commons Attribution (CC BY) license (http:/ / creativecommons.org/licenses/by/4.0/). 